\title{
Herbal antioxidants and renal ischemic-reperfusion injury; an updated review
}

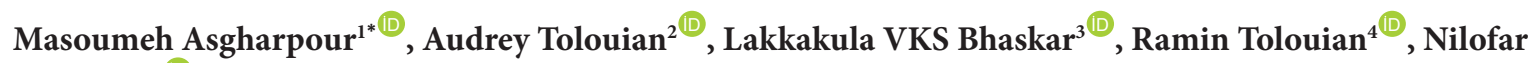 \\ Massoudi $^{5}\left({ }^{\circledR}\right.$ \\ ${ }^{1}$ Department of Nephrology, Rouhani Hospital, Babol University of Medical Sciences, Babol, Iran \\ ${ }^{2}$ School of Nursing, University of Texas at El Paso, El Paso, TX, USA \\ ${ }^{3}$ Department of Zoology, Guru Ghasidas University, Bilaspur, 495009 (CG), India \\ ${ }^{4}$ Division of Nephrology, College of Medicine, University of Arizona, Tucson, Arizona, USA \\ ${ }^{5}$ Critical Care Quality Improvement Research Center at Shahid Modarres Hospital, Department of Anesthesiology, Shahid Beheshti \\ University of Medical Sciences, Tehran, Iran
}

\section{A R T I C L E IN F O}

\section{Article Type:}

Review

\section{Article History:}

Received: 4 February 2020

Accepted: 6 May 2020

Published online: 28 May 2020

\section{Keywords:}

Acute kidney injury, Renal ischemia-reperfusion, Oxidative stress, Antioxidant

\begin{abstract}
A B S T R A C T
Renal ischemia-reperfusion (RIR) is a pathological condition due to transient restriction of blood flow to the kidneys, which is followed by the subsequent recovery of perfusion and re-oxygenation. RIR injury contributes to the progression of renal dysfunction including acute kidney injury (AKI) in native and renal allograft transplant. The generation of reactive oxygen species (ROS) during oxidative stress contributes to the occurrence of RIR. Hence, the use of antioxidant compounds can improve oxidative stress due to RIR. This review highlights herbal antioxidant efficacy against RIR injury. The findings of this study indicate that antioxidant compounds with herbal origin could reduce complications due to oxidative stress related to RIR through diminishing lipid peroxidation, decreased production of malondialdehyde (MDA), apoptosis and increasing antioxidant enzymes activity. Reducing oxidative stress with the pharmacological approach of antioxidants can be a desirable target for ameliorating RIR.
\end{abstract}

Implication for health policy/practice/research/medical education:

Antioxidants diminish the oxidative damage caused by renal ischemia-reperfusion (RIR) through inhibiting the lipid peroxidation and increasing the activity of antioxidant enzymes. Hence, targeting the oxidative stress pathway with antioxidants can be a pharmacological approach to ameliorate RIR injury.

Please cite this paper as: Asgharpour M, Tolouian A, Bhaskar LVKS, Tolouian R, Massoudi N. Herbal antioxidants and renal ischemic-reperfusion injury; an updated review. J Nephropharmacol. 2021:10(1):e03. DOI: 10.34172/npj.2021.03.

\section{Introduction}

Renal ischemia-reperfusion (RIR) is a pathological condition caused by transient restriction of blood flow to the kidneys that is followed by the subsequent recovery of perfusion and re-oxygenation. Under different conditions RIR injury may be caused by shock, cardiac arrest, sepsis, surgical interventions, and organ transplantation (1). Acute kidney injury (AKI) is recognized as a major complication of RIR, leading to a significant decrease in kidney function and a concomitant elevated serum creatinine level $(2,3)$. The occurrence of RIR injuries involves various pathways such as apoptosis, the production of reactive oxygen species (ROS), activation of neutrophils, and inflammatory mediators including cytokines and adhesion molecules $(4,5)$. Oxidative stress is one of the main events that occur during RIR, which induces cytotoxic effects; including DNA damage, proteins oxidation, lipids peroxidation, production of malondialdehyde (MDA) and induction of apoptosis $(6,7)$.

Reperfusion following ischemia leads to re-oxygenation, re-warming and a throwback to aerobic metabolism. However, the increased renal oxygen concentration in reperfusion condition can contribute to the production of $\operatorname{ROS}\left(\mathrm{H}_{2} \mathrm{O}_{2}, \mathrm{O}^{-2}\right.$ and $\left.\cdot \mathrm{OH}\right)$, resulting in injury to the functional and cytoskeletal cellular components $(8,9)$. RIR also has a significant role in early renal allograft dysfunction (10). Different strategies to reduce the complications of RIR injury through ROS scavenging is depicted in Figure 1 (11). The compounds extracted from medicinal plants including antioxidants have long been 


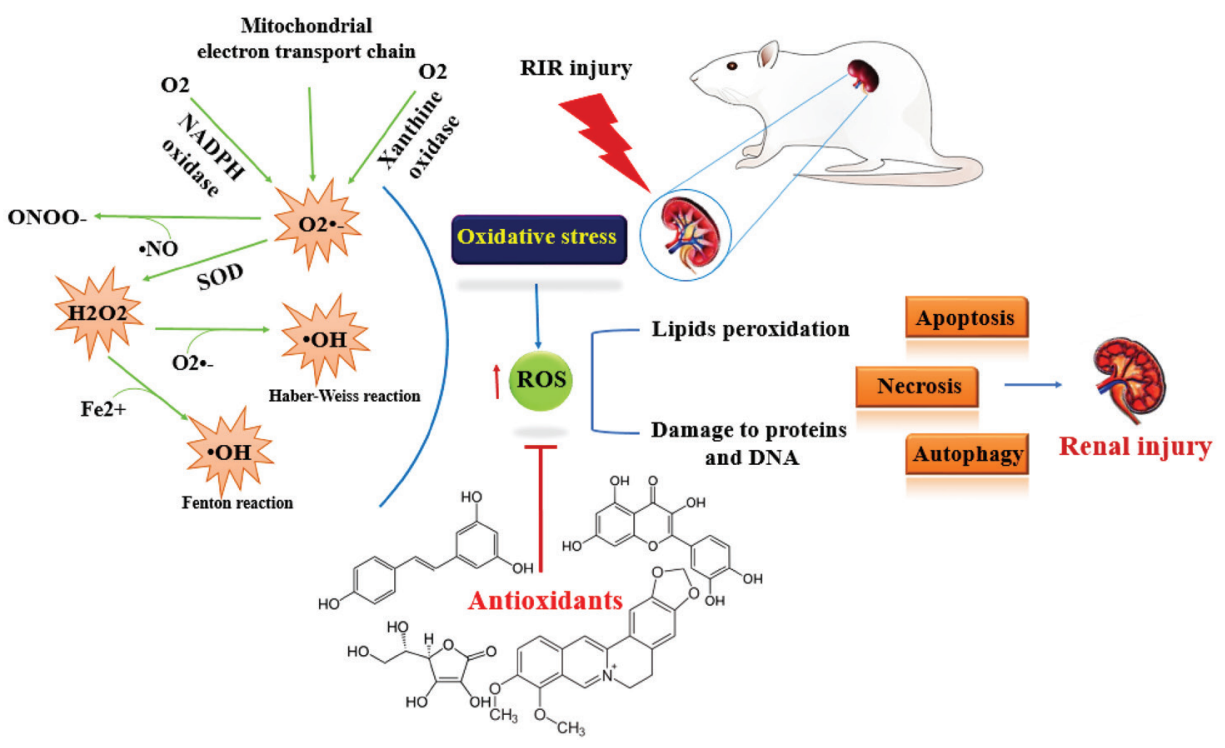

Figure 1. Oxidative stress and RIR injury, the role of antioxidants.

used as an alternative to synthetic drugs, due to their easy accessibility, fewer side effects and economic efficacy (12, 13). It has been documented that the administration of antioxidants leads to a protective effect against RIR Injury mediated oxidative injury (14). Although much progress has been made through the use of animal models, very few reviews have presented the quantitative synthesis of the effective antioxidants used against RIR injury (15-18). In the present review, we summarize the existing evidence found on the effects of the most important antioxidant compounds used for ischemia reperfusion (IR) induced renal injury (Figure 2). We also specifically highlighted some of lesser known antioxidants on this subject (Table 1).

\section{Method of study}

Relevant articles, published between 2004 to 2019, were searched from different databases such as the Google Scholar, PubMed/Medline, Web of Science, Scopus, Embase, EBSCO and Directory of Open Access Journals (DOAJ) using search terms of "renal ischemia-reperfusion", "antioxidant", "reactive oxygen species", "oxidative stress", "free radicals", and "medicinal plants".

\section{Curcumin}

Curcumin is a natural polyphenol derived from the dried rhizome of Curcuma longa (19). This compound is widely used in Asian countries due to its antimicrobial, antiinflammatory, antimutagenic, anticancer and antioxidant properties (20). Curcumin can neutralize various types of free radicals including ROS and reactive nitrogen species (RNS), and also enhances the activity of antioxidant enzymes such as glutathione (GSH), catalase (CAT) and superoxide dismutase (SOD) (21). Furthermore, curcumin reduces the production of noxious oxidants and contributes to ameliorating tubular necrosis (22). It has been proven that curcumin exhibits remarkable protective effects against RIR injury $(23,24)$. It has been demonstrated that curcumin up-regulates adaptor protein (APPL1) and subsequently suppresses phosphorylation of Akt pathway thereby protecting kidneys from IR-induced AKI (25). Experimental studies in rats with RIR showed that curcumin can ameliorate renal tubular injury through inhibiting iNOS/NO/cGMP/PKG signaling pathway (26). In addition to this, curcumin-carrying nanoparticles showed protective effects in human renal proximal tubular (HK-2) cells exposed to RIR by decreasing apoptosis, ROS level, MDA content, inhibiting the expression of Bax protein and caspase- 3 and enhancing the expression of Bcl-2 and SOD activity (27). Moreover, the renoprotective effect of curcumin in RIR injury is related to the suppression of NF-KB and activation of the JAK2/STAT3 signaling pathway (28).

\section{Luteolin}

Luteolin (3', 4', 5, 7-tetrahydroxyflavone) is a flavone compound present in fruits and vegetables. Luteolin biological activities include anti-inflammatory, anticancer and antioxidative activities (29). Several studies have indicated that treatment with luteolin ameliorates renal complications such as renal anemia, diabetic nephropathy and RIR injury $(30,31)$. In vivo and in vitro studies showed that luteolin inhibited xanthine oxidase (XO) and nicotinamide adenine dinucleotide phosphate (NADPH) oxidase activity during IR event (32). Luteolin, as an anti-inflammatory and antioxidant agent, showed nephroprotective effects in mice with RIR (33). These nephroprotective effects were evident by marked elevation in SOD and CAT levels and concomitant decrease in TNF- 


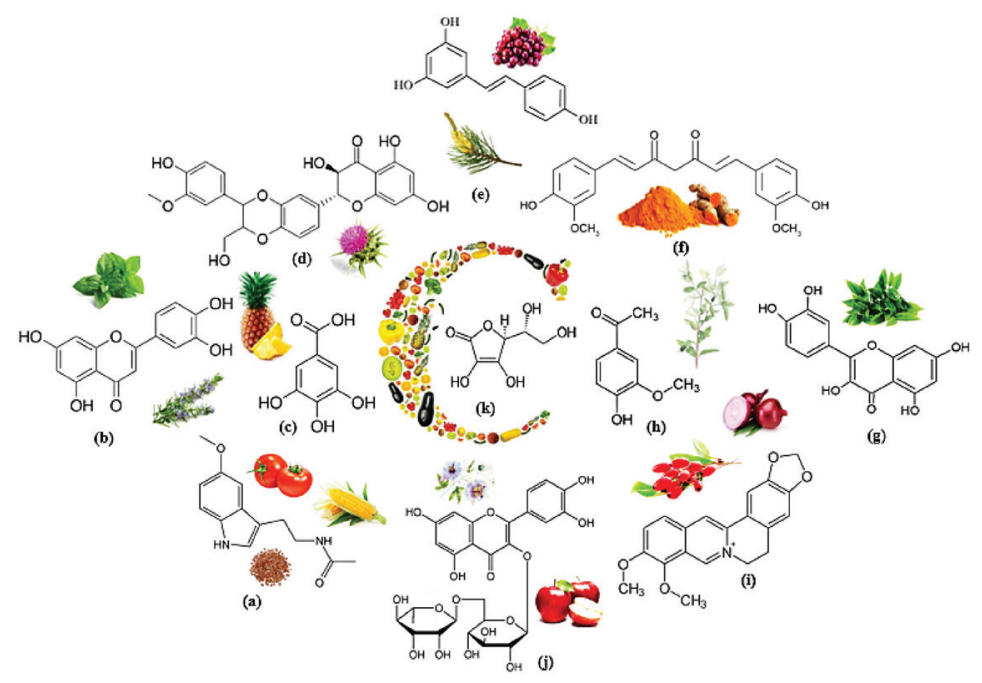

Figure 2. Chemical structure of studied antioxidants; (a) Melatonin, (b) Luteolin, (c) Gallic acid, (d) Silymarin, (e) Resveratrol, (f) Curcumin, (g) Quercetin, (h) Apocynin, (i) Berberine, (j) Rutin, (k) Vitamin C.

$\alpha$, IL -1 $\beta$, IL-6 levels (33). Further, treatment with luteolin upregulated $\mathrm{Bcl}-2$ expression and reduced Bax expression, indicating that luteolin reduced the level of apoptosis in renal tissue (34).

\section{Melatonin}

Melatonin (N-acetyl-5-methoxytryptamine) is an endogenous hormone with multiple physiological and cellular functions. Several lines of evidence indicate the presence of melatonin in plants as an antioxidant (35). Melatonin plays a major role in several pathological conditions; including cardiovascular diseases, neurodegenerative diseases, metabolic syndrome, infection and others (36). Different studies have illustrated that melatonin, as an attractive therapeutic agent, can ameliorate ischemic/reperfusion (IR)-induced disorders in membrane structure, biogenesis, mitochondrial redox state, mitophagy and related dynamics (37-39). Melatonin protects against RIR injury through its antioxidative effects as evidenced by the increased levels of antioxidative enzymes such as glutathione peroxides (GPX, GSH), CAT, SOD and neutralizing hydroxyl radicals. Interestingly, it scavenges free radicals more effectively than vitamin E (40). It has been presented that melatonin as a key modulator of cell survival, greatly increases activation of AMP-activated protein kinase (AMPK) that stimulates antioxidative enzymes and contributes to antioxidant defense (41). In addition to this, melatonin therapy improved RIR injury by preventing cell apoptosis, oxidative stress and histopathological lesions in diabetic rats with RIR injury (42). Furthermore, melatonin reduced expressions of nuclear factor erythroid 2-related factor 2 (Nrf2), silent information regulator 2 associated protein 1 (SIRT1) and heme oxygenase-1 (HO-1) by activating SIRT1/Nrf2/HO-1 signaling pathway (42). Melatonin also reduced cell injury due to RIR via reducing endoplasmic reticulum stress and Akt pathway (43).

\section{Resveratrol}

Resveratrol (3,5,4'-trihydroxystilbene) is a plant-derived molecule with potent antioxidant properties. Treatment with this polyphenol ameliorated diabetic nephropathy and renal dysfunction by reducing creatinine, urea, albumin levels and albumin to creatinine ratio (44). Studies using animal models showed that resveratrol, through its antioxidant effect or SIRT1 activation, ameliorated IR induced AKI (45). A recent study suggested that resveratrol administration at a dose of $60 \mathrm{mg} / \mathrm{kg}$ for three weeks improved levels of GSH and MDA as well as renal tissue injury in rats with RIR (46). Although the nephroprotective mechanisms of resveratrol in RIR injury are not fully clarified, some studies indicate that the resveratrol in combination with leptin, modulate the JAK/STAT signaling pathway and ameliorates RIR injury (47). Additional studies suggest that the combination of resveratrol and N-methyl-d-aspartate receptor inhibitor (DAP5) may prevent RIR injury by suppressing inflammation processes and apoptosis via NF- $\kappa B$ and CaMK/DAPK/AKT/NMDA pathways (48). In this context, resveratrol has been demonstrated to be involved in the recovery of renal function after RIR injury through the Nrf2/TLR4/NF- $\kappa B$ pathway (49).

\section{Vitamin C}

Vitamin C or ascorbic acid is one of the water-soluble vitamins, that has the ability to protect cell membranes against lipid peroxidation by acting as a ROS scavenger (50). Vitamin $\mathrm{C}$ can neutralize $\cdot \mathrm{O}^{-2}$ in the cytosol and extracellular matrix and scavenge peroxynitrite to inhibit the formation of nitrotryphophan, nitrotyrosine and 
Asgharpour et al

Table 1. The renoprotective effects of specific antioxidants against RIR injury

\begin{tabular}{|c|c|c|c|c|c|}
\hline $\begin{array}{l}\text { Antioxidant } \\
\text { compounds }\end{array}$ & Model & Ischemia time & $\begin{array}{l}\text { Reperfusion } \\
\text { time }\end{array}$ & Outcomes & Reference \\
\hline Oleanolic acid & Wistar rat & $45 \mathrm{~min}$ & $6 \mathrm{~h}$ & $\begin{array}{l}\text { - Stabilization of Nrf2/GCLc signaling } \\
\text { - Preservation of the GSH level }\end{array}$ & (15) \\
\hline Astaxanthin & Mice & $45 \mathrm{~min}$ & - & $\begin{array}{l}\text { - Reduction of tubular injury, apoptosis, necrosis and } \\
\text { inflammation via scavenging free radicals }\end{array}$ & (16) \\
\hline Naringin & $\begin{array}{l}\text { Sprague-Dawley } \\
\text { rat }\end{array}$ & $45 \mathrm{~min}$ & $24 \mathrm{~h}$ & $\begin{array}{l}\text { - Improvement of morphological alterations and renal } \\
\text { dysfunction } \\
\text { - Reduced TBARS levels and } \\
\text { - Increased renal antioxidant enzymes }\end{array}$ & (87) \\
\hline Ligustrazine & C57BL/6 mice & $50 \mathrm{~min}$ & - & $\begin{array}{l}\text { - Reduction of ROS generation } \\
\text { - Inhibition of neutrophils infiltration and apoptosis } \\
\text { - Reduction of TNF- } \alpha \text { and ICAM-1 expression }\end{array}$ & (88) \\
\hline Magnolol & $\begin{array}{l}\text { Sprague-Dawley } \\
\text { rat }\end{array}$ & $60 \mathrm{~min}$ & $24 \mathrm{~h}$ & $\begin{array}{l}\text { - Prevention of apoptosis } \\
\text { - Diminution of TNF- } \alpha\end{array}$ & (89) \\
\hline $\begin{array}{l}\text { Protocatechuic } \\
\text { acid }\end{array}$ & $\begin{array}{l}\text { Sprague-Dawley } \\
\text { rat }\end{array}$ & $45 \mathrm{~min}$ & $3 \mathrm{~h}$ & $\begin{array}{l}\text { - Reduction of kidney and serum MDA, TNF- } \alpha \text { level } \\
\text { - Improvement of total antioxidant status in serum and } \\
\text { kidney }\end{array}$ & (90) \\
\hline Syringic acid & Wistar-Albino rat & $30 \mathrm{~min}$ & $1 \mathrm{~h}$ & $\begin{array}{l}\text { - Prevention of apoptosis } \\
\text { - Reduction of TOS, OSI and MDA } \\
\text { - Amelioration of GPX activity }\end{array}$ & (91) \\
\hline Ukrain & $\begin{array}{l}\text { Sprague-Dawley } \\
\text { rat }\end{array}$ & $30 \mathrm{~min}$ & $2 \mathrm{~h}$ & $\begin{array}{l}\text { - Reduction of apoptosis and oxidative stress } \\
\text { - Regulation of the TOS/TAS activity }\end{array}$ & (92) \\
\hline Tyrosol & $\begin{array}{l}\text { Sprague-Dawley } \\
\text { rat }\end{array}$ & $45 \mathrm{~min}$ & $6 \mathrm{~h}$ & - Inhibition of iNOS-mediated oxidative stress & (93) \\
\hline \multirow[t]{2}{*}{ Salvianolic acid A } & $\begin{array}{l}\text { Sprague-Dawley } \\
\text { rat }\end{array}$ & $45 \mathrm{~min}$ & - & $\begin{array}{l}\text { - Improvement of histopathology alteration and renal } \\
\text { dysfunction } \\
\text { - Reduction of oxidative stress and apoptosis through } \\
\text { the Akt/mTOR/4EBP1 pathway }\end{array}$ & (94) \\
\hline & $\begin{array}{l}\text { Sprague-Dawley } \\
\text { rat }\end{array}$ & $60 \min$ & - & $\begin{array}{l}\text { - Prevention of peritubular capillary endothelium } \\
\text { damages } \\
\text { - Improvement of the renal hypoxia }\end{array}$ & (95) \\
\hline Salvianolic acid B & $\begin{array}{l}\text { Sprague-Dawley } \\
\text { rat }\end{array}$ & $50 \mathrm{~min}$ & $48 \mathrm{~h}$ & $\begin{array}{l}\text { - Reduction of the inflammatory process and oxidative } \\
\text { stress via PI3K/Akt signaling pathway }\end{array}$ & (96) \\
\hline Apigenin & $\begin{array}{l}\text { Sprague-Dawley } \\
\text { rat }\end{array}$ & $45 \mathrm{~min}$ & - & $\begin{array}{l}\text { - Prevention of apoptosis in vitro and in vivo through } \\
\text { PI3K/Akt pathway } \\
\text { - Improvement of histopathology alteration of kidney }\end{array}$ & (97) \\
\hline Baicalin & Wistar rat & $45 \mathrm{~min}$ & - & $\begin{array}{l}\text { - Decreased oxidative stress } \\
\text { - Inhibition of proinflammatory responses and } \\
\text { apoptosis through mitochondrial stress and TLR2/4 } \\
\text { pathway }\end{array}$ & (98) \\
\hline Lycopene & Wistar-Albino rats & $45 \min$ & $6 \mathrm{~h}$ & $\begin{array}{l}\text { - Decreased MDA, blood urea nitrogen creatinine and } \\
\text { NO levels, } \\
\text { - Improvement of histopathology alteration of kidney }\end{array}$ & $(99,100)$ \\
\hline
\end{tabular}

nitrated lipids (51). This antioxidant compound reduces oxidative stress and improves cellular function by inhibiting inflammation due to IR injury (52). Furthermore, vitamin C supplementation promoted renal nitric oxide (NO), GSH and SOD, leading to the preservation of kidney function and renal arterial reactivity against RIR (53). It has been revealed that the administration of vitamin $\mathrm{C}$ reduced RIR-induced renal injury in rats by reversing elevated serum creatinine and blood urea nitrogen (54).

\section{Berberine}

Berberine is an isoquinoline alkaloid present in some medicinal plants, including barberry, golden thread, Oregon grape, tree turmeric and Amur cork tree (55). In vitro and in vivo studies have demonstrated that berberine possesses protective effects in IR injury $(56,57)$. According to a recent study, berberine administration at the doses of 100 and $150 \mathrm{mg}$ ameliorated RIR in diabetic rats via its anti-apoptotic, anti-inflammatory and antioxidant 
properties (58). Further, this compound improved histopathological lesions and kidney dysfunction through decreased creatinine and blood urea nitrogen levels and normalized intracellular ion levels via enhancing the $\mathrm{Ca}^{2+}$ ATPase and $\mathrm{Na}^{+} / \mathrm{K}^{+}$-ATPase levels (58). In addition, in rats with RIR injury, berberine effectively improved renal function by exhibiting anti-apoptotic response through down-regulating Bax expression and upregulating Bcl-2 expression (59). Anti-apoptotic effect of berberine is also associated with the activation of the phosphatidylinositol 3-kinase/Akt signaling pathway and induction of Nrf2 that results in the protection of renal tubular cells (60).

\section{Quercetin}

Quercetin is a bioflavonoid compound with a high antioxidant property that has a protective effect against IR injury. This compound scavenges free radicals and inhibits lipid peroxidation (61). It has been noted that quercetin, in rats with RIR injury, mitigated oxidative stress by reducing MDA level and increasing GSH level as well as inhibiting endothelial nitric oxide synthase (eNOS) and NF- $\kappa B$ (62). Additionally, this flavonoid can stimulate AMPK activation by AMPK-regulated autophagy pathway and protect renal cells against IR injury in vivo and in vitro (63).

\section{Rutin}

Rutin is a flavonol found in plants such as apples, tea, passion flower and buckwheat (64). Several studies in experimental models have illustrated that the rutin has potent nephroprotective activity $(65,66)$. It has been demonstrated that rutin suppresses the pathogenesis of RIR through its radical scavenging activity. This antioxidant can remarkably prevent MDA production, enhance GSH content and manganese superoxide dismutase (MnSOD) activity in the RIR rats (67). Pretreatment with rutin showed beneficial effects against RIR by improving the oxidative status and diminishing cGMP level in the kidneys. Moreover, rutin prevents kidney dysfunction during RIR, through its potent inducible NOS (iNOS) inhibiting activity (68).

\section{Silymarin}

Silymarin is a polyphenolic compound extracted from Silybum marianum plant. Several in vivo experimental models of diabetes and drug induced nephrotoxicity have investigated the effects of silymarin $(69,70)$. Treatment with silymarin could reduce NO level, protein carbonyl and serum and tissue MDA in RIR rats indicating its antioxidant property against RIR (11). During RIR injury, silymarin pretreatment improved kidney function by reducing creatinine and blood urea nitrogen levels, inflammatory cytokines and necrosis of renal tubular cells (71). Further, treatment with silymarin increased $\mathrm{Bcl}-2$ expression and decreased Bax expression during the recovery from RIR injury. In addition to this, a combination of silymarin and palmitoylethanolamide significantly decreased renal failure due to IR via suppressing NF- $\kappa B$ and apoptosis pathways (72).

\section{Rosmarinic acid}

Rosmarinic acid is a polyphenol compound present in plants of Rosmarinus officinalis L, Origanum vulgare, Ocimum basilicum, Salvia officinalis and Melissa officinalis (73). Different studies have revealed the pharmacological and biological activities of rosmarinic acid including anticancer, anti-inflammatory, antidiabetic, antibacterial, immunomodulatory and antioxidant $(73,74)$. Rosmarinic acid has been illustrated to have a beneficial impact against nephrotoxicity (75). However, very few studies are available concerning rosmarinic acid's effect on IR injury. For instance, Ozturk et al, one of the few available, found that rosmarinic acid diminishes both the tubular and the glomerular injury in kidney of IR rats through reduction of oxidative stress and increase of antioxidant enzyme activities such as SOD and GPX (76).

\section{Gallic acid}

Gallic acid (GA) or 3,4,5 -trihydroxybenzoic acid is a phenolic acid compound with antioxidant characteristics and is found in natural products including green tea, grapes, pineapple and other plants (77). It has been demonstrated that GA pretreatment mitigates renal tubular damage in RIR rats by affecting antioxidant enzymes (78). It is also noted that GA offered renoprotective effect against RIR induced AKI through the activation of peroxisome proliferator-activated receptor gamma (PPAR- $\gamma$ ) (79).

\section{Apocynin}

Apocynin was first extracted from the roots of Apocynum cannabinum and was used as a medicine for cardiovascular diseases (80). Recently, it has been presented that apocynin has a nephroprotective potential in many models of IR (81, 82). Treatment with apocynin ameliorates renal function and antioxidant status in RIR rats via modulating the level of zinc and enhancing expression of metallothionein, which leads to a reduction of the level of IL-6, MDA, TNF- $\alpha$ and increment the SOD activity (83). Apocynin alone, or in combination with allopurinol, can reduce the IR induced renal dysfunction through inhibition of NADPH oxidase. In fact, inhibition of NADPH oxidase diminishes the formation of ${ }^{-} \mathrm{O}^{-2}$, thereby reducing oxidative stress during IR (84). Furthermore, apocynin contributes to mitigating histological lesions of RIR through glomerular damage, tubular necrosis and apoptosis as well as levels of blood urea nitrogen, creatinine and myeloperoxidase (85). Moreover, apocynin stimulates expression of Srchomology-2 domain-containing phosphatase-1 and ameliorates nitroso-redox unbalance to protect the kidney against IR injury (86). 


\section{Discussion}

Oxidative stress is identified as one of the important pathophysiological factors in IR injury. Free radicals produced during the oxidative stress process play a vital role in the stimulation of IR injury in different organs, including the kidney (101). Increased oxidative markers such as RNS and ROS may lead to deleterious impacts on the cellular structure through induction of necrosis or apoptosis (102). Moreover, inflammation pathways intensify oxidative stress, therefore the over-generation of pro-inflammatory cytokines induce tissue and cellular injury via inflammatory cell infiltration (103).

Recently, medicines such as diuretics and atorvastatin have been used to improve RIR, however, these medications don't have considerable suppressive effects against renal injury (104). It has presented that potent antioxidant ingredients with herbal origin can positively protect the kidney against IR injury (105). In fact, antioxidants such as alkaloids, vitamins, phenolics and flavonoids can significantly scavenge free radicals and ameliorate the function of antioxidant enzymes and lipid peroxidation in oxidative stress-related RIR (106).

Antioxidants diminish damage due to RIR through different mechanisms. For instance, Jiang et al reported that pretreatment with oxymatrine, an alkaloid compound, up-regulated the expression of HO-1 through the stimulation of the Nrf2 pathway and thereby protected kidney by improving RIR injury (107). The protective effect of $\mathrm{N}$-acetylcysteine on RIR may also be related to the Nrf2 pathway (108). Li et al in a recent study investigated the renoprotective effect of tea polyphenols on IR-induced renal injury, as well as its renoprotective mechanism. Their results demonstrated that pretreatment with tea polyphenols before induction of ischemia, reduce inflammatory cell infiltration and renal tubular injury through suppressing the TLR4/NF- $\kappa B$ p65 signaling pathway in RIR rats (109). In addition, PI3K/Akt, JAK/ STAT signaling $(47,96)$ and other pathways related to the regulation of apoptosis and NF- $\kappa \mathrm{B}$ pathways were considered in many studies $(49,72)$. Even some herbs, such as Allium sativum (garlic), have been shown to decrease inflammatory markers in dialysis patients, and might be appropriate interventions in future studies in RIR (110).

\section{Conclusion}

Altogether, this review adds further evidence to ongoing discussion on the benefits of herbal antioxidants in the treatment of renal injury. The evidence from this study implies that different antioxidants diminish the oxidative damage caused by RIR through inhibiting the lipid peroxidation and increasing the activity of antioxidant enzymes. Therefore, targeting the oxidative stress pathway with antioxidants can be a pharmacological approach to ameliorate RIR injury. However, it is recommended to carry out future studies in this field.
Authors' contribution

MA, NM and AT searched the literature. MA, and AT prepared the manuscript. BVKSL and RT edited the paper. All authors critically revised and approved the final manuscript.

\section{Conflicts of interest}

The authors declared no competing interests.

Ethical considerations

Ethical issues (including plagiarism, data fabrication, double publication) have been completely observed by the authors.

\section{Funding/Support}

None.

\section{References}

1. Sharfuddin AA, Molitoris BA. Pathophysiology of ischemic acute kidney injury. Nat Rev Nephrol. 2011;7:189-200. doi: 10.1038/nrneph.2011.16.

2. Chatauret N, Badet L, Barrou B, Hauet T. Ischemiareperfusion: From cell biology to acute kidney injury. Progrès en urologie. 2014;24:S4-S12. doi: 10.1016/s11667087(14)70057-0.

3. Alirezaei AH, Barough AS, Azizi T, Barough SS, Ghorbanihaghjo A, Rashtchizadeh $\mathrm{N}$, et al. Antiinflammatory effects of grape seed extract in hemodialysis patients; a pilot study. J Renal Inj Prev. 2016;6:184-7.

4. İhtiyar E, Yaşar NF, Erkasap N, Köken T, Tosun M, Öner S, et al. Effects of doxycycline on renal ischemia reperfusion injury induced by abdominal compartment syndrome. J Surg Res. 2011;167:113-20. doi: 10.1016/j.jss.2009.09.048.

5. Sadidi M, Bakhtiyari M, Alirezaei A. Effects of the Portulaca oleracea extract on gentamicin-induced nephrotoxicity in male rats. Iran Red Crescent Med J. 2019;21:e83785. doi: 10.5812/ircmj.83785.

6. Rodrigo R, Bosco C. Oxidative stress and protective effects of polyphenols: comparative studies in human and rodent kidney. Comp Biochem Physiol Part C. 2006;142:317-27. doi: 10.1016/j.cbpc.2005.11.002.

7. Bos EM, Wang R, Snijder PM, Boersema M, Damman J, $\mathrm{Fu} \mathrm{M}$, et al. Cystathionine $\gamma$-lyase protects against renal ischemia/reperfusion by modulating oxidative stress. J Am Soc Nephrol. 2013;24:759-770.

8. Saat TC, van den Akker EK, IJzermans JN, Dor FJ, de Bruin RW. Improving the outcome of kidney transplantation by ameliorating renal ischemia reperfusion injury: lost in translation? J Transl Med. 2016;14:20. doi: 10.1186/s12967016-0767-2.

9. Dare AJ, Bolton EA, Pettigrew GJ, Bradley JA, Saeb-Parsy K, Murphy MP. Protection against renal ischemia-reperfusion injury in vivo by the mitochondria targeted antioxidant MitoQ. Redox Biol. 2015;5:163-168. doi: 10.1016/j. redox.2015.04.008.

10. Snoeijs MG, van Heurn LE, Buurman WA. Biological modulation of renal ischemia-reperfusion injury. Curr Opin Organ Transplant. 2010;15:190-9.

11. Turgut F, Bayrak O, Catal F, Bayrak R, Atmaca AF, Koc A, et al. Antioxidant and protective effects of silymarin 
on ischemia and reperfusion injury in the kidney tissues of rats. Int Urol Nephrol. 2008;40:453-60. doi: 10.1007/ s11255-008-9365-4.

12. Lourenço SC, Moldão-Martins M, Alves VD. Antioxidants of natural plant origins: From sources to food industry applications. Molecules. 2019;24:4132. doi: 10.3390/ molecules24224132.

13. Xu DP, Li Y, Meng X, Zhou T, Zhou Y, Zheng J, et al. Natural antioxidants in foods and medicinal plants: extraction, assessment and resource. Int J Mol Sci. 2017;18:96. doi: 10.3390/ijms 18010096.

14. Sezgin G, Öztürk G, Güney Ş, Sinanoğlu O, Tunçdemir M. Protective effect of melatonin and 1, 25-dihydroxyvitamin D3 on renal ischemia-reperfusion injury in rats. Ren Fail. 2013;35:374-9. doi: 10.3109/0886022X.2012.760409.

15. Long C, Yang J, Yang H, Li X, Wang G. Attenuation of renal ischemia/reperfusion injury by oleanolic acid preconditioning via its antioxidant, anti-inflammatory, and anti-apoptotic activities. Mol Med Rep. 2016;13:4697-704. doi: $\quad 10.3892 / \mathrm{mmr} .2016 .5128$.

16. Qiu X, Fu K, Zhao X, Zhang Y, Yuan Y, Zhang S, et al. Protective effects of astaxanthin against ischemia/ reperfusion induced renal injury in mice. J Transl Med. 2015;13:28. doi: 10.1186/s12967-015-0388-1.

17. Palipoch S. A review of oxidative stress in acute kidney injury: protective role of medicinal plants-derived antioxidants. Afr J Tradit Complement Altern Med. 2013;10:88-93.

18. Tavafi M. Suggestions for attenuation of renal ischemia reperfusion injury based on mechanisms involved in epithelial cells damages. J Nephropharmacol. 2015;4:1-3.

19. Perrone D, Ardito F, Giannatempo G, Dioguardi M, Troiano G, Lo Russo L, et al. Biological and therapeutic activities, and anticancer properties of curcumin. Exp Ther Med. 2015;10:1615-23. doi: 10.3892/etm.2015.2749.

20. Nagpal M, Sood S. Role of curcumin in systemic and oral health: An overview. J Nat Sci Biol Med. 2013;4:3-7. doi: 10.4103/0976-9668.107253.

21. Hewlings SJ, Kalman DS. Curcumin: a review of its' effects on human health. Foods. 2017;6:92. doi: 10.3390/ foods6100092.

22. Trujillo J, Chirino YI, Molina-Jijón E, Andérica-Romero AC, Tapia E, Pedraza-Chaverrí J. Renoprotective effect of the antioxidant curcumin: Recent findings. Redox Biol. 2013;1:448-56. doi: 10.1016/j.redox.2013.09.003.

23. Yeh JH, Yang YC, Wang JC, Wang D, Wang JJ. Curcumin attenuates renal ischemia and reperfusion injury-induced restrictive respiratory insufficiency. Transplant Proc. 2013;45:3542-3545.

24. Liu FH, Ni WJ, Wang GK, Zhang JJ. Protective role of curcumin on renal ischemia reperfusion injury via attenuating the inflammatory mediators and Caspase-3. Cell Mol Biol. 2016;62:95-9.

25. Fan Y, Chen H, Peng H, Huang F, Zhong J, Zhou J. Molecular mechanisms of curcumin renoprotection in experimental acute renal injury. Front Pharmacol. 2017;8:912. doi:10.3389/fphar.2017.00912

26. Liu F, Ni W, Zhang J, Wang G, Li F, Ren W. Administration of curcumin protects kidney tubules against renal ischemiareperfusion injury (RIRI) by modulating nitric oxide (NO) signaling pathway. Cell Physiol Biochem. 2017;44:401-11. doi: $10.1159 / 000484920$.
27. Xu Y, Hu N, Jiang W, Yuan HF, Zheng DH. Curcumincarrying nanoparticles prevent ischemia-reperfusion injury in human renal cells. Oncotarget. 2016;7:87390-87401.

28. Zhang J, Tang L, Li GS, Wang J. The anti-inflammatory effects of curcumin on renal ischemia-reperfusion injury in rats. Ren Fail. 2018;40:680-6. doi: $10.1080 / 0886022 X .2018 .1544565$.

29. Aziz N, Kim MY, Cho JY. Anti-inflammatory effects of luteolin: a review of in vitro, in vivo, and in silico studies. J Ethnopharmacol. 2018;225:342-58. doi: 10.1016/j. jep.2018.05.019.

30. Li S, Jiang H, Han B, Kong T, Lv Y, Yang Q, et al. Dietary luteolin protects against renal anemia in mice. J Funct Foods. 2019:103740. doi: 10.1016/j.jff.2019.103740.

31. Chen L, Tian G, Tang W, Luo W, Liu P, Ma Z. Protective effect of luteolin on streptozotocin-induced diabetic renal damage in mice via the regulation of RIP140/NF-кB pathway and insulin signalling pathway. J Funct Foods. 2016;22:93-100.

32. Gelabert-Rebato M, Wiebe JC, Martin-Rincon M, Gericke N, Perez-Valera M, Curtelin D, et al. Mangifera indica l. Leaf extract in combination with luteolin or quercetin enhances vo2peak and peak power output, and preserves skeletal muscle function during ischemia-reperfusion in humans. Front Physiol. 2018;9:740. doi: 10.3389/fphys.2018.00740.

33. Hong X, Zhao X, Wang G, Zhang Z, Pei H, Liu Z. Luteolin treatment protects against renal ischemia-reperfusion injury in rats. Mediators Inflamm. 2017;2017: 9783893. doi: 10.1155/2017/9783893.

34. Liu Y, Shi B, Li Y, Zhang H. Protective effect of luteolin against renal ischemia/reperfusion injury via modulation of pro-inflammatory cytokines, oxidative stress and apoptosis for possible benefit in kidney transplant. Med Sci Monit. 2017;23:5720-5727.

35. Shi H, Love J, Hu W. Melatonin in Plants. Front Plant Sci. 2017;8:1666. doi: 10.3389/fpls.2017.01666.

36. Sánchez-Barceló E, Mediavilla M, Tan D, Reiter RJ. Clinical uses of melatonin: evaluation of human trials. Curr Med Chem. 2010;17:2070-95.

37. Reiter RJ, Mayo JC, Tan DX, Sainz RM, Alatorre-Jimenez M, Qin L. Melatonin as an antioxidant: under promises but over delivers. J Pineal Res. 2016;61:253-78. doi: 10.1111/ jpi.12360.

38. Ma Z, Xin Z, Di W, Yan X, Li X, Reiter RJ, et al. Melatonin and mitochondrial function during ischemia/reperfusion injury. Cell Mol Life Sci. 2017;74:3989-9.

39. Panah F, Ghorbanihaghjo A, Argani H, Haiaty S, Rashtchizadeh N, Hosseini L, et al. The effect of oral melatonin on renal ischemia-reperfusion injury in transplant patients: A double-blind, randomized controlled trial. Transpl Immunol. 2019;57:10124.

40. Claustrat B, Leston J. Melatonin: Physiological effects in humans. Neurochirurgie. 2015;61:77-84.

41. Tka KHA, Boussaid AM, Kessabi K, Kammoun R, Messaoudi I, Mazgar SG, et al. Involvement of AMP-activated protein kinase in the protective effect of melatonin against renal ischemia reperfusion injury. Turk J Biol. 2016;40:837-44. doi:10.3906/biy-1507-59.

42. Shi S, Lei S, Tang C, Wang K, Xia Z. Melatonin attenuates acute kidney ischemia/reperfusion injury in diabetic rats by activation of the SIRT1/Nrf2/HO-1 signaling pathway. Biosci Rep. 2019;39: BSR20181614. doi: 10.1042/ 


\section{BSR20181614.}

43. Tka KHA, Boussaid AM, Zaouali MA, Kammoun R, Bejaoui M, Ghoul Mazgar S, et al. Melatonin modulates endoplasmic reticulum stress and Akt/GSK3-beta signaling pathway in a rat model of renal warm ischemia reperfusion. Anal Cell Pathol. 2015;2015:635172. doi: 10.1155/2015/635172.

44. Park EJ, Pezzuto JM. The pharmacology of resveratrol in animals and humans. Biochim Biophys Acta Mol Basis Dis 2015;1852:1071-113.

45. Kitada M, Koya D. Renal protective effects of resveratrol. Oxid Med Cell Longev. 2013;2013:568093. doi: 10.1155/2013/568093.

46. Baltaci A, Gokbudak H, Baltaci S, Mogulkoc R, Avunduk M. The effects of resveratrol administration on lipid oxidation in experimental renal ischemia-reperfusion injury in rats. Biotech Histochem. 2019;94:592-9. doi: 10.1080/10520295.2019.1612091.

47. Erkasap S, Erkasap N, Bradford B, Mamedova L, Uysal O, Ozkurt M, et al. The effect of leptin and resveratrol on JAK/ STAT pathways and Sirt-1 gene expression in the renal tissue of ischemia/reperfusion induced rats. Bratisl Lek Listy. 2017;118:443-8.

48. Xu Y, Zhang B, Xie D, Hu Y, Li HL, Zhong LL, et al. Nanoparticle-mediated dual delivery of resveratrol and DAP5 ameliorates kidney ischemia/reperfusion injury by inhibiting cell apoptosis and inflammation. Oncotarget. 2017;8:39547-39558.

49. Li J, Li L, Wang S, Zhang C, Zheng L, Jia Y, et al. Resveratrol alleviates inflammatory responses and oxidative stress in rat kidney ischemia-reperfusion injury and $\mathrm{H} 2 \mathrm{O} 2$-induced NRK-52E cells via the Nrf2/TLR4/NF- $\kappa \mathrm{B}$ pathway. Cell Physiol Biochem. 2018;45:1677-89. doi: 10.1159/000487735.

50. Dennis JM, Witting PK. Protective role for antioxidants in acute kidney disease. Nutrients. 2017;9:718. doi: 10.3390/ nu9070718.

51. Chen AY, Lü JM, Yao Q, Chen C. Entacapone is an antioxidant more potent than vitamin $\mathrm{C}$ and vitamin $\mathrm{E}$ for scavenging of hypochlorous acid and peroxynitrite, and the inhibition of oxidative stress-induced cell death. Med Sci Monit. 2016;22:687-696. doi: 10.12659/MSM.896462.

52. Davis JL, Paris HL, Beals JW, Binns SE, Giordano GR, Scalzo RL, et al. Liposomal-encapsulated ascorbic acid: Influence on vitamin $\mathrm{C}$ bioavailability and capacity to protect against ischemia-reperfusion injury. Nutr Metab Insights. 2016;9:25-30. doi: 10.4137/NMI.S39764.

53. Zhu YB, Zhang YP, Zhang J, Zhang YB. Evaluation of vitamin $C$ supplementation on kidney function and vascular reactivity following renal ischemic injury in mice. Kidney Blood Press Res. 2016;41:460-70.

54. Korkmaz A, Kolankaya D. The protective effects of ascorbic acid against renal ischemia-reperfusion injury in male rats. Ren Fail. 2009;31:36-43. doi: 10.1080/08860220802546271.

55. Jin Y, Khadka DB, Cho WJ. Pharmacological effects of berberine and its derivatives: a patent update. Expert Opin Ther Pat. 2016;26:229-43. doi: $10.1517 / 13543776.2016 .1118060$.

56. Martins RM, Pinto Rolo A, Soeiro Teodoro J, Furtado E, Caetano Oliveira R, Tralhão JG, et al. Addition of berberine to preservation solution in an animal model of ex vivo liver transplant preserves mitochondrial function and bioenergetics from the damage induced by ischemia/ reperfusion. Int J Mol Sci. 2018;19:284. doi: 10.3390/ ijms 19010284 .
57. Yu Y, Zhang M, Hu Y, Zhao Y, Teng F, Lv X, et al. Increased bioavailable berberine protects against myocardial ischemia reperfusion injury through attenuation of NFKB and JNK signaling pathways. Int Heart J. 2018;59:1378-88.

58. Kumaş M, Eşrefoğlu M, Karataş E, Duymaç N, Kanbay $\mathrm{S}$, Ergün IS, et al. Investigation of dose-dependent effects of berberine against renal ischemia/reperfusion injury in experimental diabetic rats. Nefrología. 2019;39:411-23.

59. Zheng H, Lan J, Li J, Lv L. Therapeutic effect of berberine on renal ischemia-reperfusion injury in rats and its effect on Bax and Bcl-2. Exp Ther Med. 2018;16:2008-12. doi: 10.3892/etm.2018.6408.

60. Zhang X, Liang D, Lian X, Jiang Y, He H, Liang W, et al. Berberine activates Nrf2 nuclear translocation and inhibits apoptosis induced by high glucose in renal tubular epithelial cells through a phosphatidylinositol 3-kinase/ Akt-dependent mechanism. Apoptosis. 2016;21:721-36. doi: 10.1007/s10495-016-1234-5.

61. Baghel SS, Shrivastava N, Baghel RS, Agrawal P, Rajput S. A review of quercetin: antioxidant and anticancer properties. World J Pharm Pharmaceutical Sci. 2012;1:146-60.

62. Kenan Kinaci M, Erkasap N, Kucuk A, Koken T, Tosun M. Effects of quercetin on apoptosis, NF- $\kappa \mathrm{B}$ and NOS gene expression in renal ischemia/reperfusion injury. Exp Ther Med. 2012;3:249-54. doi: 10.3892/etm.2011.382.

63. Chen BL, Wang LT, Huang KH, Wang CC, Chiang CK, Liu SH. Quercetin attenuates renal ischemia/reperfusion injury via an activation of AMP-activated protein kinase-regulated autophagy pathway. J Nutrition Biochem. 2014;25:1226-34. doi: 10.1016/j.jnutbio.2014.05.013.

64. Ganeshpurkar A, Saluja AK. The pharmacological potential of rutin. Saudi Pharm J. 2017;25:149-64.

65. Huang YC, Horng CT, Chen ST, Lee SS, Yang ML, Lee CY, et al. Rutin improves endotoxin induced acute lung injury via inhibition of iNOS and VCAM-1 expression. Environ Toxicol. 2016;31:185-91. doi: 10.1002/tox.22033.

66. Kamel KM, Abd El-Raouf OM, Metwally SA, Abd El-Latif HA, El-sayed ME. Hesperidin and rutin, antioxidant citrus flavonoids, attenuate cisplatin-induced nephrotoxicity in rats. J Biochem Mol Toxicol. 2014;28:312-9. doi: 10.1002/ jbt.21567.

67. Korkmaz A, Kolankaya D. Protective effect of rutin on the ischemia/reperfusion induced damage in rat kidney. J Surg Res. 2010;164:309-15. doi: 10.1016/j.jss.2009.03.022.

68. Korkmaz A, Kolankaya D. Inhibiting inducible nitric oxide synthase with rutin reduces renal ischemia/reperfusion injury. Can J Surg. 2013;56:6-14.

69. Stolf AM, Cardoso CC, de Morais H, de Souza CEA, Lomba LA, Brandt AP, et al. Effects of silymarin on angiogenesis and oxidative stress in streptozotocin-induced diabetes in mice. Biomed Pharmacother. 2018;108:232-43. doi: 10.1016/j.biopha.2018.09.042.

70. Bouhalit S, Kechrid Z, Elfeki A. Effect of silymarin extracted from Silybum marianum on nickel hematotoxicity and nephrotoxicity in male albino wistar rats. Int J Pharm Pharm Res. 2017;9:84-9.

71. Tan J, Hu J, He Y, Cui F. Protective role of silymarin in a mouse model of renal Ischemia-Reperfusion injury. Diagn Pathol. 2015;10:198. doi: 10.1186/s13000-015-0436-4.

72. Impellizzeri D, Bruschetta G, Ahmad A, Crupi R, Siracusa R, Di Paola R, et al. Effects of palmitoylethanolamide and silymarin combination treatment in an animal model of kidney ischemia and reperfusion. Eur J Pharmacol. 
2015;762:136-49. doi: 10.1016/j.ejphar.2015.05.010.

73. Alagawany M, El-Hack MEA, Farag MR, Gopi M, Karthik $\mathrm{K}$, Malik YS, et al. Rosmarinic acid: modes of action, medicinal values and health benefits. Anim Health Res Rev. 2017;18:167-76. doi: 10.1017/S1466252317000081.

74. Boonyarikpunchai W, Sukrong S, Towiwat P. Antinociceptive and anti-inflammatory effects of rosmarinic acid isolated from Thunbergia laurifolia Lindl. Pharmacol Biochem Behav. 2014;124:67-73.

75. Bayomy NA, Elbakary RH, Ibrahim MA, Abdelaziz EZ. Effect of lycopene and rosmarinic acid on gentamicin induced renal cortical oxidative stress, apoptosis, and autophagy in adult male albino rat. Anat Rec . 2017;300:1137-49. doi: 10.1002/ar.23525.

76. Ozturk H, Ozturk H, Terzi EH, Ozgen U, Duran A, Uygun I. Protective effects of rosmarinic acid against renal ischaemia/reperfusion injury in rats. J Pak Med Assoc. 2014;64:260-5.

77. Malinda K, Sutanto H, Darmawan A. Characterization and antioxidant activity of gallic acid derivative. AIP Conf Proc. 2017;1904:020030.

78. Canbek M, Ustüner MC, Kabay S, Uysal O, Ozden H, Bayramoğlu G, et al. The effect of gallic acid on kidney and liver after experimental renal ischemia/reperfusion injury in the rats. Afr J Pharm Pharmacol. 2011;5:1027-33.

79. Singh JP, Singh AP, Bhatti R. Explicit role of peroxisome proliferator-activated receptor gamma in gallic acidmediated protection against ischemia-reperfusion-induced acute kidney injury in rats. J Surg Res. 2014;187:631-9. doi: 10.1016/j.jss.2013.11.1088.

80. Stefanska J, Pawliczak R. Apocynin: molecular aptitudes. Mediators Inflamm. 2008;2008:106507. doi: $10.1155 / 2008 / 106507$.

81. Duran A, Ciloglu S, Sehirli O, Yigit A, Buyukdogan $\mathrm{H}$, Duran A, et al. Apocynin and dimethyl sulfoxide synergistically protect against ischemia-reperfusion injury in a rat hind limb ischemia-reperfusion model. Eur J Plast Surg. 2017;40:507-12. doi: 10.1007/s00238-017-1309-8.

82. Kapoor M, Sharma N, Sandhir R, Nehru B. Effect of the NADPH oxidase inhibitor apocynin on ischemiareperfusion hippocampus injury in rat brain. Biomed Pharmacother. 2018;97:458-72. doi: 10.1016/j. biopha.2017.10.123.

83. Hu B, Wu Y, Tong F, Liu J, Shen X, Shen R, et al. Apocynin alleviates renal ischemia/reperfusion injury through regulating the level of zinc and metallothionen. Biol Trace Elem Res. 2017;178:71-8.

84. Choi E, Jung H, Kwak K, Yeo J, Yi S, Park C, et al. Effects of allopurinol and apocynin on renal ischemia-reperfusion injury in rats. Transplant Proc. 2015;47;1633-1638. doi: 10.1016/j.transproceed.2015.06.007.

85. Altintas R, Polat A, Vardi N, Oguz F, Beytur A, Sagir $M$, et al. The protective effects of apocynin on kidney damage caused by renal ischemia/reperfusion. J Endourol. 2013;27:617-24. doi: 10.1089/end.2012.0556.

86. Li Z, Wang Y. Effect of NADPH oxidase inhibitor-apocynin on the expression of Src homology-2 domain-containing phosphatase-1 (SHP-1) exposed renal ischemia/reperfusion injury in rats. Toxicol Rep. 2015;2:1111-6. doi: 10.1016/j. toxrep.2015.07.019.

87. Singh D, Chopra K. The effect of naringin, a bioflavonoid on ischemia-reperfusion induced renal injury in rats. Pharmacol Res. 2004;50:187-93.
88. Feng L, Ke N, Cheng F, Guo Y, Li S, Li Q, et al. The protective mechanism of ligustrazine against renal ischemia/reperfusion injury. J Surg Res. 2011;166:298-305. doi: $\quad 10.1016 /$ j.jss.2009.04.005.

89. Tang CY, Lai CC, Huang PH, Yang AH, Chiang SC, Huang $\mathrm{PC}$, et al. Magnolol reduces renal ischemia and reperfusion injury via inhibition of apoptosis. Am J Chin Med. 2017;45:1421-39.

90. Yüksel M, Yıldar M, Başbuğ M, Çavdar F, Çıkman Ö, Akşit HZ, et al. Does protocatechuic acid, a natural antioxidant, reduce renal ischemia reperfusion injury in rats? Ulus Travma Acil Cerrahi Derg. 2017;23:1e6.

91. Sancak EB, Akbas A, Silan C, Cakir DU, Turkon H, Ozkanli SS. Protective effect of syringic acid on kidney ischemia-reperfusion injury. Ren Fail. 2016;38:629-35. doi: 10.3109/0886022X.2016.1149868.

92. Aras B, Akçilar R, Koçak FE, Koçak H, Savran B, Metineren $\mathrm{H}$, et al. Effect of ukrain on ischemia/reperfusion-induced kidney injury in rats. J Surg Res. 2016;202:267-75.

93. Wang P, Zhu Q, Wu N, Siow YL, Aukema H, O K. Tyrosol Attenuates ischemia-reperfusion-induced kidney injury via inhibition of inducible nitric oxide synthase. J Agric Food Chem. 2013;61:3669-75. doi: 10.1021/jf400227u.

94. Song Y, Liu W, Ding Y, Jia Y, Zhao J, Wang F, et al. Salvianolic acid A ameliorates renal ischemia/reperfusion injury by activating Akt/mTOR/4EBP1 signaling pathway. Am J Physiol Renal Physiol. 2018;315:F254-F62.

95. Zhang Z, Qi D, Wang X, Gao Z, Li P, Liu W, et al. Protective effect of salvianolic acid $A$ on ischaemia reperfusion acute kidney injury in rats through protecting against peritubular capillary endothelium damages. Phytother Res. 2018;32:103-14. doi: 10.1002/ptr.5954.

96. Ma Z, Xia H, Cui S, Yu J. Attenuation of renal ischemic reperfusion injury by salvianolic acid B via suppressing oxidative stress and inflammation through PI3K/Akt signaling pathway. Braz J Med Biol Res 2017;50: e5954.

97. Wang X, Wang W, Wang JZ, Yang C, Liang CZ. Effect of apigenin on apoptosis induced by renal ischemia/ reperfusion injury in vivo and in vitro. Ren Fail. 2018;40:498-505.

98. Lin M, Li L, Li L, Pokhrel G, Qi G, Rong R, et al. The protective effect of baicalin against renal ischemiareperfusion injury through inhibition of inflammation and apoptosis. BMC Complement Altern Med. 2014;14:19. doi: 10.1186/1472-6882-14-19.

99. Kaya C, Karabulut R, Turkyilmaz Z, Sonmez K, Kulduk G, Gülbahar Ö, et al. Lycopene has reduced renal damage histopathologically and biochemically in experimental renal ischemia-reperfusion injury. Ren Fail. 2015;37:13905.

100. Sadic M, Atilgan HI, Aydin A, Koca G, Korkmaz M, Karakan $\mathrm{T}$, et al. Scintigraphic, histopathologic and biochemical evaluation of lycopene effects on renal ischemia reperfusion injury in rats. Srp Arh Celok Lek. 2017;145:153-8.

101. Choi EK, Jung H, Kwak KH, Yi SJ, Lim JA, Park SH, et al. Inhibition of oxidative stress in renal ischemia-reperfusion injury. Anaesth Analg. 2017;124:204-13.

102. Kezic A, Spasojevic I, Lezaic V, Bajcetic M. Mitochondriatargeted antioxidants: future perspectives in kidney ischemia reperfusion injury. Oxid Med Cell Longev. 2016;2016:2950503. doi: 10.1155/2016/2950503.

103. Small DM, Bennett NC, Roy S, Gabrielli BG, Johnson DW, Gobe GC. Oxidative stress and cell senescence combine to 
cause maximal renal tubular epithelial cell dysfunction and loss in an in vitro model of kidney disease. Nephron Exp Nephrol. 2012;122:123-30.

104. Zhao L, Xu L, Tao X, Han X, Yin L, Qi Y, et al. Protective effect of the total flavonoids from Rosa laevigata michx fruit on renal ischemia-reperfusion injury through suppression of oxidative stress and inflammation. Molecules. 2016;21:952.

105. Erturk N, Elbe H, Dogan Z, Aktas S, Demirbilek S, Ozturk F. Curcumin prevents renal oxidative stress and tissue damage induced by renal ischemia/reperfusion in rats. Int Surg J. 2018;5:3192-7.

106. Aslanturk OS, Celik TA. Antioxidant, cytotoxic and apoptotic activities of extracts from medicinal plant Euphorbia platyphyllos L. J Med Plants Res. 2013;7:1293304.

107. Jiang G, Liu X, Wang M, Chen H, Chen Z, Qiu T. Oxymatrine ameliorates renal ischemia-reperfusion injury from oxidative stress through Nrf2/HO-1 pathway. Acta Cir Bras. 2015;30:422-9. doi: 10.1590/S0102-865020150060000008.

108. Zhang L, Zhu Z, Liu J, Zhu Z, Hu Z. Protective effect of $\mathrm{N}$-acetylcysteine (NAC) on renal ischemia/reperfusion injury through Nrf2 signaling pathway. J Recept Signal Transduct. 2014;34:396-400.

109. Li YW, Zhang Y, Zhang L, Li X, Yu JB, Zhang HT, et al. Protective effect of tea polyphenols on renal ischemia/ reperfusion injury via suppressing the activation of TLR4/ NF- $\mathrm{B}$ p65 signal pathway. Gene. 2014;542:46-51. doi: 10.1016/j.gene.2014.03.021.

110. Zare E, Alirezaei A, Bakhtiyari M, Mansouri A. Evaluating the effect of garlic extract on serum inflammatory markers of peritoneal dialysis patients: a randomized double-blind clinical trial study. BMC Nephrol. 2019;20:26. doi:10.1186/ s12882-019-1204-6

Copyright $\odot 2021$ The Author(s); Published by Published by Society of Diabetic Nephropathy Prevention. This is an open-access article distributed under the terms of the Creative Commons Attribution License (http://creativecommons.org/licenses/by/4.0), which permits unrestricted use, distribution, and reproduction in any medium, provided the original work is properly cited. 